\title{
PENGUATAN KARAKTER RELIGIUS MAHASISWA MELALUI PENDIDIKAN AL ISLAM KEMUHAMMADIYAHAN (STUDI KASUS DI UNIVERSITAS MUHAMMADIYAH PALOPO)
}

\author{
Amriani \\ Program Studi Pendidikan Anak Usia Dini, FKIP, Universitas Muhammdiyah Palopo \\ amrianianjek03@gmail.com
}

\begin{abstract}
Abstrak
Penelitian ini adalah penelitian kualitatif yanga mengkaji tentang peranan pendidikan agama Islam di perguruan tinggi sebagai mata kuliah umum (MKU) untuk menguatkan karakter religius mahasiswa. Tujuan penelitian ini untuk menganalisis dan mendeskripsikan peran pendidikan Al-Islam kemuhammadiyahan di Universitas Muhammadiyah Palopo. Faktor pendukung dan penghambat peran pendidikan AIK dan respon mahasiswa terhadap peran Pendidikan Al-Islam Kemuhammadiyaan di Universitas Muhammadiyah Palopo. penelitian ini menggunakan jenis penelitian kualitatif dengan metode deskriptif analisis. Teknik pengumpulan data menggunakan wawancara, observasi dan dokumentasi. Data yang didapatkan dianalisis melalui reduksi data, penyajian data dan verifikasi/kesimpulan. Hasil penelitian yang mengacu pada rumusan masalah menunjukkan bahwa Proses pendidikan Al-Islam Kemuhammadiyaan tidak terlepas dari kerjasama dari semua pihak. Yaitu, khususnya para dosen pengampu yang senantiasa berpartisifasi aktif dalam membina, membimbing para mahasiswa untuk menjadi masyarakat yang beakhlak mulia, bermartabat serta mampu memahami eksistensinya sebagai khalifah dimuka bumi ini.
\end{abstract}

Kata Kunci: Pendidikan Al-Islam Kemuhammadiyaan, Karakter Religius.

\begin{abstract}
This research is qualitative research that examines the role of Islamic religious education in universities as a public course (MKU) to strengthen the religious character of students. The purpose of this study is to analyze and describe the role of al-Islama education to muhammadiyahan at muhammadiyah Palopo University. Supporting factors and inhibiting the role of AIK education and student response to the role of Al-Islam Kemuhammadiyaan Education at Muhammadiyah Palopo University. This research uses qualitative research type with descriptive method of analysis. Data collection techniques using interviews, observations and documentation. The data obtained is analyzed through data reduction, data presentation and verification/conclusion. The results of the study that refers to the formulation of the problem shows that the educational process of Al-Islam Kemuhammadiyaan is inseparable from the cooperation of all parties. That is, especially the lecturers who are always actively participating in fostering, guiding students to become a society of noble character, dignity and able to understand its existence as a caliph on the face of the earth.
\end{abstract}

Keywords: Al-Islam Kemuhammadiyaan Education, Religious Character

\section{PENDAHULUAN}

Pendidikan merupakan titik sentral sekaligus memiliki peran strategis untuk membangun dan mencerahkan generasi bangsa dalam rangka mencapai hakekat kemanusiannya di persada bumi ini. Nilainilai pendidikan akan mengantarkan manusia untuk mencapai hakekat kemanusiannya. Manusia adalah makhluk paripurna yang dikaruniai akal dan pikiran oleh Allah SWT untuk pengejaewantahan nilai-nilai moral sekaligus merupakan aset bangsa yang harus tetap eksis dalam kancah pergolakan dunia. Fitra Manusia tidak terlepas dari nilai-nilai kemuliaan ketika dikelola sesuai dengan fitra kemanusiaannya sehingga menghasilkan karakter yang kuat untuk membangun peradaban yang berkualitas. Penguatan pendidikan karakter harus dalakukan secara continu dan dibutuhkan kerja sama dari semua pihak untuk membangun pondasi 
yang kokoh . dalam hal ini sebagai berikut; Pertama: Knowing the good, mengetahui yang baik, bisa mudah diajarkan, sebab pengetahuan bersifat kognitif. Mengajarkan yang baik, adil, bernilai, yang berarti dapat memberikan pemahaman dengan jernih kepada pembelajar apa itu kebaikan, keadilan, kejujuran, toleransi, nilai dan lainlain. Kedua: Feeling and loving the good. Setelah knowing the good, akan tumbuh feeling and loving the good, yakni bagaimana merasakan dan mencintai kebaikan menjadi power dan engine yang bisa membuat senang terbiasa mau berbuat kebaikan. Ketiga: Acting the good tindakan kebaikan, setelah melalui proses mengerti dan mencintai kebaikan yang melibatkan dimensi kongnitif dan afektif. Melalui tindakan pengalaman kebaikan ini positif. Keempat: Keteladanan Aspek knowing the good feeling and loving the good dan acting the good pembelajaran butuh keteladanan dari lingkungan sekitarnya. Manusia lebih banyak belajar dan mencontoh dari apa yang ia lihat dan alami (Iswan, 2018)

Tujuan dari Pendidikan karakter tidak terlepas dari pembentukan nilai-nilai akhlakul karimah yang akan mengantarkan peserta didik menjadi pribadi yang senatiasa berfikir positif dan bertanggung jawab (Yasin Nurfalah, 2016). Sementara itu, UU 202003 tentang Sikdiknas menyatakan bahwa Pendidikan nasional berfungsi mengembangkan kemampuan dan membentuk watak serta peradaban bangsa yang bermartabat dalam rangka mencerdaskan kehidipan bangsa, bertujuan untuk berkembangnya potensi peserta didik agar menjadi manusia yang beriman dan bertakwa kepada Tuhan Yang Maha Esa, berakhlak mulia, sehat, berilmu, cakap, kreatif, mandiri, dan menjadi warga negara yang demokratis serta bertanggung jawab. Oleh karena itu, ketika pendidikan ini bersinergitas dalam menumbuh kembangkan pendidikan karakter maka nilai-nilai pendidikan di Indonesia memiliki kontribusi sehingga mampu membawa bangsa ini menuju bangsa yang bermartabat, bermoral, dan jauh dari degradasi atau keterpurukan secara terus menerus mengerogaoti bangsa ini. Oleh karena itu, penanaman nilai-nilai karakter reigius sangat penting daam kehidupan generasi bangsa, karena nilai-nilai karakter religius berimplikasi pada perangai, tabiat, kepribadian, kecenderungan seseorang untuk senantiasa mendekatkan diri dalam ketaatan, melaksanakan ajaran agama sesuai dengan keyakinannya serta toransi terhadap pemeluk agama lain (Khomsilawati, 2017).

Pada masa perkembangan Era globalisasi dewasa ini, yang harus ditekankan adalah pembentukan karakter generasi bangsa, karena karakter yang baik akan menghasilkan generasi yang tangguh, bermoral, berakhlak mulia sehingga berimplikasi pada keberlangsungan masa depan bangsa. Akan tetapi, realitas yang terjadi masih jauh dari nilai-nilai kemulian, baik itu dari pendidikan formal maupun pendidikan non formal. Oleh karena itu, pendidikan Islam memiliki peran penting dengan membawa visi mulia sebagai Pranata yang kokoh, berwibawa, efektif, dan kridibel dalam mewujudkan cita-cita ajaran Islam (Nata, 2010; 44). Oleh karena itu peran pendidikan Islam sangat penting dalam membangun paradaban yang bermartabat sesuai dengan tuntunan Rasulullah saw. hal yang paling mendasar dalam mengokohkan generasi Islam adalah penanaman nilai-nilai tauhid (Qordawi, 2004). Dengan dengan Al-Islam kemuhammadiyahan sebagai pondasi untuk menguatkan karakter religius mahasiswa. Transformasi nilai-nilai Islam harus terus digaungkan karena hal ini untuk mengatarkan manusia untuk mencapai peribadi yang agung sebgai khalifah di bumi. Pendidikan karakter sangat erat kaitannya dengan pendidikan agama. Agama memiliki peran istimewa dalam sebagai pegangan, untuk menstabilitaskan karakter peserta didik. Dengan demikian pendidikan karakter berfokus kepada pengenalan, pendalaman, dan pelaksanaan beragama (Suryanti \& Widayanti, 2018)

Al-Islam kemuhammadiyahan adalah mata kuliah yang wajid untuk diikuti oleh semua mahasiswa dan diharapkan dapat memeberikan contribusi yang signifikan terhadap pembentukan karakter mahasiswa, di mana mahasiswa mampu berpikir kreatif dan secara kritis sehingga mampu 
membedakan mana yang baik dan buruk sesuai dengan norma-norma yang berlaku. Dengan demikian, peserta didik akan terarah dalam mengaktualisasikan diri dalam kehidupan sosial, bergaul secara wajar berinteraksi secara positif dan memiliki perubahan kearah yang lebih baik secara psikis dan emosional. Oleh karena itu, butuh pendampingan yang estra dari berbagai macam pihak yang dapat mengantarkan mahasiswa menjadi manusia seutuhnya yang dapat memahami kemanusianya sehingga jauh dari sikap buruk yang akan melenakan dan tergilas oleh zaman.

Esensi dari pendidikan karakter mengarah kepada kepedulian religius, kepedulian religius dan dan kepekaan dalam beragama Islam yang baik dibutuhkan strategi. Sehingga pendidikan Al-Islam dan Kemuhammadiyaan adalah salah satu adalah konsep untuk menguatkan karakter religius mahasiswa (Huda, 2019). Al-Islam kemuhammadiyahan di Perguruan Tinggi memiliki peran vital untuk menambah keyakinan mahasiswa dalam meningkatkan keimanan , dan ketakwaan Allah swt, berakhlak mulia, dan memiliki pemikiran yang tajam secara holistik dan dinamis, mengaktifkan diri dalam meningkatkan toleransi beragama serta melejitkan potensi dalam membangun bangsa (Rohim, 2016). Oleh karena itu, pendidikan Islam di perguruan tinggi merupakan langkah awal dalam menetukan arah hidupnya. Hal ini dipertegas oleh Philip H. Phenix, bahwa dibutuhkan kematangan pada prosese internalisasi nilai-nilai pada pesera didik. Ada enam pola makna esensial yang harus ditanamkan kepada mereka, yaitu; (a) makna symbolic yakni kemampuan berbahasa dan berhitung, (b) makna empiric yakni kemampuan untuk memaknai benda-benda melalui proses penjelajahan dan penyelidikan empiris, (c) makna esthetic yaitu kemampuan memaknai keindahan seni dan fenomena alam, (d) makna ethic yaitu kemampuan memaknai baik dan buruk, (e) makna synoetic yaitu kemampuan berfikir logis, yakni kemampuan untuk beragama atau berfilsafat. (Phenix : 1964)

Perguruan tinggi merupakan wadah dalam mengejewantahkan potensi yang dimiliki peseta didik dan mengembangkan potensinya dalam berbagai bidang pendidikan. Mata kuliah umum akan memperluas wawasan mahasiswa, memahami pendidikan secara generalis sehingga tetap memahami nilai kemanusiaan yang melekat pada dirinya (Muhdi, 2014) Al-Islam kemuhammadiyahan sebagai mata kuliah umum (MKU) berperan penting dalam penguatan karakter mahasiswa. Oleh karena itu, mata kuliah Al-Islam dan Kemuhammadiyahan di perguruan tinggi Muhammadiyah memiliki peran vital untuk penanmemegang peranan yang sangat penting untuk menciptakan generasi yang berkepribadia dan berakhlakul karimah karena indikator keberhasilan Al-Islam dan kemuhammadiyahan terletak dari perubahan perilaku tabiat, perangai karakter mahasiswa (Samsidar, Darliana Sormin, 2019).

Mahasiswa adalah aset bangsa generasi pelanjut estafet kepemimpinan untuk mengharumkan nama baik bangsa tercinta ini, menjadi negara yang berdaulat adil dan makmur. Al -Islam kemuhammadiyahan merupakan suatu proses dalam meningkatkan keimanan mahasiswa dan penananman nilai-nilai spiritual yang berorientasi pada akhlakul karimah. Namu melihat realita yang ada bahwa Al Islam kemuhahammadiyahan sebagai MKU tidak memiliki daya tarik sebagai minat utama bagi mahasiswa, hanya saja untuk memenuhi syarat kulaih. Hal ini merupakan tantangan terbesar bagi para dosen yang harus lebih estra dan memiliki kreativitas tinggi dalam melejitkan potensi mahasiswa sehingga Al-Islam kemuhammadiyahan di perguruan tinggi memiliki daya tarik dan sebagai kebutuhan paling mendasar untuk meningkatkan kualitas sumber daya manusia. Karakter merupakan nilai-nilai kemulian manusia yang berhubungan dengan sang maha pencipta, diri pribadi, serta makhluk lainnya, lingkungan negara yang terjewantahkan dalam perkataan dan dapat diimplementasikan dalam perbuatan berdasarkan norma-norma agama, hukum, tata krama, budaya dan adat istiadat (Iriany 
Jur, 2014).

Tujuan dari penelitian ini adalah untuk menganalisis dan mendeskripsikan proses peran Al -Islam kemuhammadiyaahan, faktor pendukung dan faktor penghambat pelaksanan pembinaan keagamaan serta respon mahasiswa terhadap pendidikan $\mathrm{Al}$ Islam kemuhammadiyahan di Universitas Muhammadiyah Palopo. Sedangkan manfaat penelitian ini terbagi menjadi dua yaitu manfaat secara praktis dan manfaat secara teoritis. Secara praktis penelitian ini adalah sebagai bahan acuan pada pengelola perguruan tinggi (Universitas Muhammadiyah Palopo untuk membenahi dan meningkatkan kualitas proses pembelajaran serta memberikan sumbangsi pemikiran pada para pengelola perguruan tinggi Muhammadiyah. Sedangkan secara teoritis adalah sebagai bahan referensi bagi para dosen AIK Universitas Muhammadiyah Palopo pada khususnya dan seluruh wilayah Indonesia pada umumnya, untuk menciptakan dan mengelola Al Islam kemuhammadiyahan yang mendapatkan hasil yang maksimal dapat memberikan motivasi dalam meningkatkan keinginantahuan oleh para pembaca tentang deskripsi pelaksanaan pembelajaran AIK di Universitas Muhammadiyah Palopo.

\section{METODE}

Penelitian ini dengan pendekatan kualitatif dengan jenis deskpritif analisis. Penelitian kualitatif merupakan prosedur penelitian yang mengahasilakan data deskriptif yang berupa kata-kata tertulis atau lisan dari orang-orang atau pelakau yang dapat diamati. Hal ini dijelaskan oleh Moleong (2011) bahwa penelitian kualitatif adalah penelitian yang bermaksud untuk memahami fenomena tentang apa yang dialami oleh subjek penelitian misalnya perilaku, persepsi, motivasi, tindakan, dll., secara holistik dan dengan cara deskripsi dalam bentuk kata-kata dan bahasa, pada suatu konteks khususnya yang alamiah dan memanfaatkan berbagai metode alamiah.

Penelitian ini dilakukan di Universitas Muhammadiyah yang berlokasi di Kota Palopo provinsi Provinsi Sulawesi Selatan. Data yang di peroleh terdapat dua sumber yaitu data primer dan sekunder. Data primer pada penelitian ini dikumpulkan berdasarkan permasalahan utama yang terkait dengan proses pembelajaran AIK, faktor pendukung dan faktor penghambat Proses Pembelajaran Al-Islam Kemuhammadiyaan dan respon Mahasiswa terhadap pelaksanaan Pembelajaran AlIslam Kemuhammadiyahan di Universitas Muhammadiyah Palopo. Sedangkan data sekunder diperoleh dari data yang sudah ada dan mempunyai hubungan masalah yang dapat diteliti yang meliputi literaturliteratur yang ada baik berbentuk dokumen maupun pengamatan peneliti. Data dikumpulkan menggunakan teknik interview (wawancara), observasi (pengamatan), dan dokumentasi, selanjutnya data yang terkumpul dianalisis.

\section{HASIL DAN PEMBAHASAN}

Berdasarkan hasil temuan di lapangan bahwa proses pelaksanaan pembelajaran Al-Islam Kemuhammadiyahan (AIK) Universitas Muhammadiyah Palopo merupakan proses pembelajaran yang telah terealisasi secara continu dan merupakan mata kuliah wajib yang harus diikuti oleh seluruh mahasiswa, sekaligus sebagai proses penguatan karakter mahasiswa. AlIslam dan Kemuhammadiyahan (AIK) di Universitas Muhammadiyah Palopo memiliki peran strategis dalam bentuk mata kuliah umum, dan menjadi ruh dari seluruh kegiatan pendidikan di Universitas. Proses pendidikan AIK harus mampu mewujudkan empat pilar pendidikan, yaitu to know, to do, to be, to life together, dan didukung oleh semangat learning throughout life (belajar sepanjang hayat), sehingga mampu mengantarkan civitas akademika memiliki karakter pribadi muslim yang ideal. Keberhasilan pendidikan AIK ini menjadi salah satu indikator ketercapaian misi pendidikan Universitas Muhammadiyah Palopo, sebagai bagian dakwah untuk mewujudkan Islam sebagai rahmatan lil 'alamin.

Melaksanakan sebuah aktivitas baik itu disebuah lembaga formal maupun non formal semua memiliki konsekuensi, dalam hal ini, pelaksanaan pendidikan Al-Islam Kemuhammadiyahan adalah sebuah 
keniscayaan akan mendapat faktor penghambat dan faktor pendukung. Oleh karena itu, pelaksanaan pendidikan AIK di Universitas Muhammadiyah Palopo akan dilaksanakan secara malaksimal, mengoptimalkan segala sarana prasarana dan serta membutuhkan dukungan dari semua pihak. Sehingga, yang akan menjadi faktor penghamabat dalam pelaksanaan pendidikan AIK tidak berdampak negatif serta tidak menggaanggu stabilitas peroses pendidikan AIK di Universitas Muhammadiyah Palopo

Berdasarkan hasil penelitian melalui wawancara, observsi dan dokumentasi di Universitas Muhammadiyah Palopo, terdapat beberapa faktor pendukung dan penghmbat. pada proses pelasanaan pendidikan AIK di Unversitas Muhammadiyah Palopo. Hal ini, yang menjadi faktor pendukung dan dapat melancararkan pelasanaan proses pendidikan adalah adanya kerja sama dari semua pihak, yaitu pihak lembaga itu sendiri dan dosen yang mengampu mata kuliah AIK. Semua bahu membahu serta berpartisipasi aktif tanpa pamri dalam melaksanakan proses pendidikan AIK dengan niat hanya ingin mentransformasikan ilmu dan nilai-nilai kepada seluruh mahasiswa sehingga menjadi mahasiswa yang berakhlak mulia.

Bieesanz (1969) menjelaskan bahwa kerja sama merupakan suatau usaha yang dilakukan secara bersama-sama yang berkelanjutan pada dua atau lebih orang untuk menyelenggarakan suatau tugas atau untuk mencapai suatu tujuan yang diharapkan bersama. Kejasama dari semua pihak dalam proses pembinaan sangat membantu dalam menghasilkan target pencapaian yang maksimal. Pembina akan melaksanakan kewajibannya sesuai dengan profesinya yaitu menanamkan nilai-nilai Islam kepada mahasiswa agar mampu memahami eksistensinya sebagai makhluk Allah yang senantiasa beramar ma'ruf nahimungkar. AIK sebagai praksis pendidikan nilai hendaknya dipahamidalam kerangka pendidikanmenghidupkan nilai (living values education) yang menekankan pada penciptaan lingkungan berbasis nilai. Oleh karena itu, pengembangan AIK sebagai praksis pendidikan nilai meniscayakan kehadiran suatu sistem dalam mana nilai- nilai tertentu hidup. Salah satu bagian dari sistem itu adalah dosen harus meekat pada dirinya sifat-sitat asasi pendidik ikhlas, taqwa, memiliki ilmu pengetahuan, santun/ pemaaf, dan menyadari tanggung jawab (Arifin, 2015).

Berdasarkan hasil analisis penelitian terkait respon mahasiswa terhadap pelaksanaan pendidikan AIK cukup bangus (positif). Hal tersebut, sesuai dengan hasil wawancara peneliti dengan informan. Respon tersebut dapat dilihat dari sikap peserta pada saat pelaksanaan proses pembelajaran berlangsung. Hanya saja, Perhatian mahasiswa sering saja teralihkan apabila mereka berkumpul dengan temantemannya, terkadang mereka asik bercerita dan tidak memperhatikan dengan baik apa yang disampaikan oleh dosen atau pemateri.

Para dosen atau semua yang terkait melakukan segala upaya dalam membimbing sekaligus mengarahkan mahasiswa serta memotivasi dalam memperbaiki dirinya. Sebagai makhluk sosial seorang dosen yang sadar akan tanggung jawabnya sebagai khalifah dalam rangka memanusiakan manusia, merubah karakter buruk menjadi lebih baik. Mereka melakukannya dengan segenap jiwa raga, ikhlas tanpa mengaharapkan balasan. Namun, tidak cukup hanya dengan dosen saja yang aktif, yang diperlukan adalah kerjasama dari kedua belah pihak untuk mencapai hasil yaang lebih baik. Kedua belah pihak ini, adalah seorang dosen dan mahasiswa, harus saling menguatkan.

Faktor yang menentukan keberhasilan pengajaran adalah dari sisi yang diajar. Mereka harus berusaha dan kemauan yang kuat untuk memperbaiki diri, tidak hanya menyerahkan pada dosen, tanpa kemauan dan usaha yang sungguh-sungguh tidak akan dapat mencapai hasil pembinaan yang optimal. Hovland menjelaskan bahwa, perubahan sikap seseorang akan tergantung pada sejauh mana dia menanggapi suatu dorongan atau rangsangan (stimulus) itu diperhatikan, dipahami dan diterima (Azwar, 1995). Para dosen AIK harus memiliki kreativitas tinggi untuk lebih 
mampu mentransformasikan alumni dan mentrasnformasikan nilai-nilai kebaikan pada mahasiswa. Oleh karena itu, para dosen AIK harus memiliki kompetensi.

\section{SIMPULAN}

Berdasarkan hasil penelitian dapat disimpulkan, proses pendidikan Al-Islam Kemuhammadiyahan yang berparadigma spritualitas tauhid dan etika sosial, dengan misi keagamaan dan kemanusiaan menguatkan karakter religius mahasiswa. Faktor pendukung pada proses pelaksanaan pembelajaran Al-Islam kemuhammadiyahan tidak terlepas dari kerjama sama semua pihak. Para dosen cukup mumpuni dalam

\section{DAFTAR PUSTAKA}

Arifin, S. 2015. Rekonstruksi Al-IslamKemuhammadiyahan (Aik) Perguruan Tinggi Muhammadiyah Sebagai Praksis Pendidikan Nilai. EDUKASI: Jurnal Penelitian Pendidikan Agama dan Keagamaan, 13(2), 201-221. https://doi.org/10.32729/edukasi.v13i 2.239

Azwar, S. 1995. Sikap Manusia. Yogyakarta: Pustaka Pelajar.

Moleong, L. J. (2011). Metodologi Penelitian Kualitatif. Bandung: PT Remaja Rosdakarya.

Nata, Abuddin. 2010. Ilmu Pendididikan Islam. Jakarta: Kencana Pranada Media Group. Michel Foucault. (n.d.).

Qordawi, Y. 2012. Islam Agama Peradaban, Solo: Era Intermedia.

Rohim, A. 2016. Peranan Pendidikan Agama Islam (PAI) di Perguruan Tinggi Melalui Pendekatan Fenomenologis. Nidhomul Haq, 1(3), 127-135. Arifin, S. (2015). Rekonstruksi Al-IslamKemuhammadiyahan (Aik) Perguruan Tinggi Muhammadiyah Sebagai Praksis Pendidikan Nilai. EDUKASI: Jurnal Penelitian Pendidikan Agama dan Keagamaan, 13(2), 201-221. https://doi.org/10.32729/edukasi.v13i 2.239

Huda, H. 2019. Membangun Karakter Islami Melalui Al Islam dan Kemuhammadiyahan [Studi Analisis mengelola pembelajaran Al-Islam Kemuhammadiyahan serta memliki SDM yang memadai dalam mentransformasikan nilai-nilai keislaman pada mahasiswa. Respon mahasiswa terhadap matakuliah pendidikan Al-Islam dan Kemuhammadiyahan kurang bagus (negatif). Oleh karena itu, diperlukan upaya dan kerja sama dari semua pihak untuk mengolola pembelajaran ini. Pelaksanaa pengajaran AIK dapat memberikan kontribusi kapada seluruh mahasiswa dan civitas akademik perguruan tinggi karena dapat mampu menanamkan nilai-nilai keislaman yang dapat menguatkan karakter generasi bangsa yaitu mahasiswa.

Perpres No. 87 Tahun 2017 tentang Penguatan Pendidikan Karakter (PPK)]. Tarlim: Jurnal Pendidikan Agama Islam, 2(1), 55. https://doi.org/10.32528/tarlim.v2i1.2 071

Iriany Jur. 2014. Pendidikan Karakter sebagai Upaya Revitalisasi Jati Diri Bangsa. IriaPendidikan Karakter sebagai Upaya Revitalisasi Jati Diri Bangsa, 08(01), 54-85.

Iswan, I. B. 2018. penguatan Pendidikan Karakter Perspektif Islam Dalam Era Millenial IR. 4.0., áÚîï Çá(1), 26216477.

https://doi.org/10.1017/CBO97811074 15324.004

Khomsilawati, S. 2017. Penguatan Karakter Religius Dalam Pembelajaran Sastra Melalui Adaptasi Kearifan Lokal. Prosiding SENASBASA, 1, 370-375.

Muhdi. 2014. Posisi Mata Kuliah Pendidikan Agama Islam (Pai) Dalam Kurikulum Perguruan Tinggi Umum Menurut Sk Dirjen Dikti No . 43 \& 44 Tahun 2006 (Sebuah Pemikiran Tentang Langkah Implementasi Peran). Jurnal intekna, 2014(1), 1101.

Samsidar, Darliana Sormin, M. P. 2019. AlMuaddib: Jurnal Ilmu-Ilmu Sosial dan Keislaman Peranan Mata Kuliah Al Islam Tapanuli Selatan, 4(2), 296305.

Suryanti, E. W., \& Widayanti, F. D. 2018. 
Penguatan Pendidikan Karakter

Berbasis Religius. Seminar Nasional

Hasil Riset, (September), Malang:

FKIP, Universitas Wisnuwardhana

Malang.

Yasin Nurfalah. 2016. Urgensi Nilai-nilai

Pendidiksn karakter, 27(1), 170-187. 